\title{
Antioxidative activity of probiotics
}

\author{
Arkadiusz Hoffmann, Paulina Kleniewska, Rafał Pawliczak
}

Department of Immunopathology, Faculty of Biomedical Sciences and Postgraduate Training, Medical University of Lodz, Lodz, Poland

Submitted: 5 September 2017; Accepted: 28 March 2018;

Online publication: 21 November 2019

Arch Med Sci 2021; 17 (3): 792-804

DOI: https://doi.org/10.5114/aoms.2019.89894

Copyright $\odot 2019$ Termedia \& Banach

\begin{abstract}
Probiotics are defined as live microorganisms that have a beneficial effect on health by exhibiting quantitative and qualitative effects on intestinal microflora and/or modification of the immune system. A strain is considered probiotic if it demonstrates a series of clinically proven health benefits. In recent years, the number of studies related to the antioxidant properties of probiotics has significantly increased. Antioxidants are substances that inhibit the degree of oxidation of molecules and cause the transformation of radicals into inactive derivatives. The incorrect or inefficient antioxidant mechanisms results in oxidative stress and may occur in the course of many diseases such as diabetes, atherosclerosis, inflammatory bowel disease or damage to the heart, brain or transplanted organs. Correct functioning of antioxidant mechanisms seems to be crucial for the proper functioning of our body; therefore, probiotics should be carefully investigated for potential antioxidant properties.
\end{abstract}

Key words: reactive oxygen species, oxidative stress, microbiota.

\section{Introduction}

The term reactive oxygen species (ROS) refers mainly to free radicals derived from molecular oxygen, and a few other chemically reactive molecules, which originate during the gradual reduction of molecular oxygen. Oxygen-centered radicals (e.g. superoxide anion $-\mathrm{O}_{2}{ }^{--}$, hydroxyl radical $-{ }^{-} \mathrm{OH}$, or hydroperoxyl $-\mathrm{HO}_{2}^{*}$ ) are regarded as distinct from oxygen-centered non-radicals, such as hydrogen peroxide $\left(\mathrm{H}_{2} \mathrm{O}_{2}\right)$, singlet oxygen $\left({ }^{1} \mathrm{O}_{2}\right)$ or ozone $\left(\mathrm{O}_{3}\right)$. Inside the human body, ROS function as regulators and mediators to ensure correct cell functioning [1, 2]. The role of ROS in numerous biological processes depends on their concentration, and overproduction can easily induce damage to proteins, nucleic acids or lipids through free radical reactions [3-6]. Therefore, in the event of excess ROS production, protective antioxidant mechanisms are activated. Oxidative stress appears if these mechanisms work incorrectly or inefficiently [7], resulting in an imbalance between antioxidant and oxidant levels, where oxidation is prevalent [8]. This imbalance affects human health and may contribute to chronic diseases or aging.

Oxidative stress is known to result in the occurrence of molecular mechanisms of diabetes, atherosclerosis, inflammatory bowel disease (IBD) and damage to the heart, brain or transplanted organs [9]. Inactivation of glyceraldehyde 3-phosphate dehydrogenase (GAPDH) leads to the inhibition of glycolysis and a subsequent reduction of ATP level.

\author{
Corresponding author: \\ Rafał Pawliczak MD, PhD \\ Department of \\ Immunopathology \\ Medical University of Lodz \\ 7/9 Zeligowskiego St \\ Bldg 2, Room 177 \\ 90-752 Lodz, Poland \\ E-mail: rafal.pawliczak@csk. \\ umed.lodz.pl
}


Other consequences of oxidative stress include a decrease in reduced glutathione (GSH) to glutathione disulfide (GSSG) ratio, reduction of total glutathione (tGSH) level and formation of glutathione conjugates. In turn, active transport of GSSG and conjugates contributes to ATP consumption and reduced intracellular glutathione $[10,11]$. Additionally, oxidative stress is often accompanied by mitochondrial membrane permeability, and abnormal activity of $\mathrm{Na} / \mathrm{K}$-ATPase and the calcium pump. Elevated oxidative stress can ultimately result in apoptosis or cell necrosis. Therefore, all possible mechanisms and new methods of oxidative stress reduction are of great interest [12, 13].

Microorganisms have become popular food supplements because they exhibit a great number of beneficial effects. Improvement of the gastrointestinal microbial environment [14], competitive exclusion of pathogens [15] and stimulation of the host immune system [16] are just some of the many positive effects attributed to probiotics. Probiotic strains have been reported to scavenge hydroxyl radicals and superoxide anions and produce antioxidants. The most widely studied strains are currently Bifidobacterium and Lactobacillus $[17,18]$.

\section{In vitro studies}

In a study of bacterial samples containing cell free extracts or intact cells, Amaretti et al. [19] assessed the inhibition of linolenic acid peroxidation (TAALA), ascorbate autoxidation (TAAAA), superoxide dismutase (SOD) and cellular content of GSHt, GSH and GSSG. The authors investigated the antioxidant properties of a wide range of bacterial species, including Lactobacillus (11 strains), Bifidobacterium (seven strains), Lactococcus (six strains), Streptococcus thermophilus (10 strains). The results indicate that the antioxidant mechanism and degree of antioxidant activity are typical for a particular bacterial strain. The duration of the study was reduced by using an initial in vitro analysis which allowed the best material to be selected for further studies in rats. Most of the strains, except for Lactococcus spp., were characterized by low levels of intracellular glutathione. Interestingly, although the majority of bifidobacteria did not produce any detectable amounts of tGSH, Bifidobacterium animalis produced the greatest amount of all the tested strains. The other strains which produced sufficient tGSH were Streptococcus thermophilus EI-16, S. thermophilus MB 410, Lactococcus lactis ssp. diacetilactis MB 447, and L. lactis ssp. cremoris. The greatest SOD activity was demonstrated by Lactococcus strains, whereas Lactobacillus spp. and Streptococcus thermophilus showed the greatest TAALA and TAAAA production. These results enabled the selection of Lactobacillus brevis, L. acidophilus and Bifidobacterium animalis subsp. lactis for subsequent in vivo animal studies.

It should be noted that the bioaccessibility of antioxidants is a very important parameter [20]. Cell-free extracts isolated from 38 strains, mostly from Bifidobacterium longum spp., were evaluated for their antioxidant capacity. Oxygen radical absorbance capacity (ORAC) was found to be a highly strain-specific feature characteristic of $B$. longum subsp. longum CUETM 172; however, this value is not in accordance with that of milk fermented with this particular strain. The ORAC assay is a suitable analytical method for determining antioxidant potential across a broad range of substances in food, nutraceuticals and pharmaceutical products. The test is based on a fluorescein dye used to monitor antioxidant activity and can be easily read on a microplate reader. An analysis of bacterial survival also revealed that survival rate in the gastrointestinal tract (GIT) is much more important for bioaccessibility of antioxidants than the antioxidant capacity of cell-free extracts. Studies suggest that improved bioaccessibility may be associated with the dead portions of probiotic bacteria: the strain with the lowest survival rate, specifically $B$. longum subsp. longum PRO 16-10, exhibits the highest level of antioxidant bioaccessibility, while the strain with the best survival rate, $B$. longum subsp. longum CUETM 172, exhibits the lowest bioaccessibility. Oral administration of $B$. breve Yakult (BBY) appeared to prevent transepidermal water loss and significantly suppress oxidation of lipids, proteins and the hydrogen peroxide level [21]; however, its antioxidant capacity was unchanged. Hence, it could be said that the antioxidative effect of BBY does not result from antioxidant capacity but from prevention of ROS generation.

Another study [22] investigated the antioxidative effect of Lactobacillus acidophilus (ATCC 4356) and Bifidobacterium longum (ATCC 15708) in the form of intracellular cell-free extracts or intact cells. Both forms demonstrated inhibition of linoleic acid peroxidation, ranging from $38 \%$ to $48 \%$, which indicates that Lactobacillus acidophilus and Bifidobacterium longum have a strong antioxidative effect. Additionally, both intracellular cell-free extracts and intact cells possess radical scavenging ability, which contributes to the antioxidative effect of the examined strains. The antioxidant properties of Lactobacillus fermentum, E-3 and E-18 were evaluated in the presence of ROS [23]. As a result, the probiotic strains showed a significantly longer survival time than the non-antioxidative strain, due to elevated glutathione level and MnSOD expression. Antioxidative Streptococcus thermophilus AO54 is also associated with 
the presence of MnSOD, as confirmed by metal supplementation studies [24], which indicate that $S$. thermophilus AO54 expresses MnSOD in a growth-phase-dependent manner.

Some studies argue that antioxidant effects are not unique to probiotics and that pathogenic microorganisms share the same features. However, Lactobacillus strains have been found to have higher total antioxidant activity than other examined strains [25]. Research has shown that obligatory heterofermentative lactobacilli are characterized by the strongest antioxidant activity [26]. Furthermore, they conclude that antioxidative activity is a strain-specific feature but can be related to the fermentation type of probiotic bacteria. Interestingly, it was revealed that green tea infusion had a positive effect on the antioxidant properties of probiotic products with Streptococcus thermophilus, Lactobacillus acidophilus LA-5, and Bifidobacterium animalis. Probiotic antioxidant capacity, measured with ferric-reducing antioxidant power (FRAP) and diphenyl picrylhydrazyl (DPPH) methods, was enhanced in a dose-dependent manner [27]. Interestingly, one of the most prevalent species in human saliva, Lactobacillus salivarius, exhibits relatively high antioxidative parameters, as documented by total antioxidant assay or (DPPH) radical scavenging assay [28], whereas L. salivarius ssp. salivarius BCRC 14759 is even able to reduce the colon adenocarcinoma cell viability to less than $50 \%$ [29].

Although lactobacilli and bifidobacteria are prevalent, they are not the only beneficial probiotic organisms. Studies have also addressed the possible antioxidant and ROS scavenging activity of Saccharomyces boulardii probiotics. A study by Suryavanshi et al. [30] identified which active compounds are responsible for the antioxidant potential of S. boulardii. The results of in vitro DPH, NBT and total phenolic and flavonoid content assays confirmed that crude extract is characterized by high antioxidant activity. Subsequently, the researchers induced oxidative stress with $\mathrm{H}_{2} \mathrm{O}_{2}$ in A549 lung cancer cells. Saccharomysces boulardii extract was found to reduce the formation of ROS in the A549 cell model, as measured by fluorescence. A further quantitative evaluation of S. boulardii extracts, performed with NBT and DPPH assays, indicated that antioxidant activity was significantly higher than that of ethyl acetate, DCM extracts and butanol.

Co-expression of the CAT gene katA from LaCtobacillus sakei and SOD gene sodA from Streptococcus thermophilus in Lactobacillus rhamnosus AS 1.2466 was planned to achieve high oxidative resistance [31]. The L. rhamnosus cells were incubated with $\mathrm{H}_{2} \mathrm{O}_{2}$ to initiate oxidative stress and their survival rate was evaluated. The modified bacteria were found to have a 400 -fold higher survival rate than controls, which suggests that the combination of SOD and CAT expressed in probiotic bacteria can enhance the oxidative resistance of the host.

Elsewhere [32], lactic acid bacteria (LAB) were investigated for their capacity to prevent oxidative DNA damage in HT29 cells. These bacteria, usually associated with milk products, are able to provide lactic acid as a major end-product of carbohydrate fermentation [33]. Lactic acid bacteria constitute a crucial group of microorganisms used throughout the food industry. Plumbagin and hydrogen peroxide were used to induce oxidative stress. Among 55 strains evaluated with plate growth inhibition assays, the strongest effect was observed in Streptococcus thermophilus species. DNA damage prevention did not correlate with the individual $\mathrm{O}_{2}^{(-)}$ resistance of the bacteria. Additionally, it was revealed that only viable bacteria are able to reduce oxidative damage, unlike heat inactivated cells. Interestingly, LAB separated from HT29 by a permeable filter remain effective, which confirms that they release protective factors into the medium. The LAB started to manifest their protective properties when their titer was equal to $3 \times 10^{7}$ cells $/ \mathrm{ml}$, indicating that $L A B$ antioxidant activity depends on their concentration. Most of the tested strains are characterized by bestowing a significant protective effect against oxidative damage, but others also damaged HT29 DNA. A similar study [34] on HT-29 cells revealed that both Lactobacillus acidophilus 606 polysaccharide fraction and heatkilled L. acidophilus 606 demonstrated high antioxidant activity.

The cellular antioxidant activity (CAA) assay proved to be a suitable method for evaluating the antioxidant activity of 10 Lactobacillus strains [35]. A further comparison with other in vitro antioxidant activity assays, including DPPH radical scavenging, inhibition of linoleic acid peroxidation (ILAP), hydroxyl radical scavenging (HRS) and reducing power (RP) assays, found that lactobacilli cell-free supernatants exhibit antioxidant activities that can be quantitatively assessed in HepG2 cells. Of all the administered methods, L. rhamnosus CCFM 1107 demonstrated a strong antioxidative effect, similar to $L$. rhamnosus GG ATCC 53103, which served as positive control for all of the assays. Lactobacillus helveticus CD6 intracellular cell-free extract was also found to have strong antioxidative ability [36]. It demonstrated $27.5 \pm 3.7 \%$ inhibition of ascorbate autoxidation and the ability to chelate metal ions, and its DPPH radical scavenging activity was found to be about $24.7 \pm 10.9 \%$ for intact cells.

The antioxidative potential of soy milk, fermented with other probiotic bacterial strains, con- 
stitutes another noteworthy research subject [37]. Various oxidant parameters have been evaluated, including hydrogen peroxide and superoxide anion scavenging, inhibition of ascorbate autoxidation and reducing activity. The antioxidative effects of soya milk fermented with individual probiotic strains or strains used in combination were always significantly stronger than the effects of unfermented soya milk. All the examined strains (L. acidophilus CCRC 14079, Bifidobacterium longum B6, B. infantis CCRC 14633 and Streptococcus thermophilus CCRC 14085) exert antioxidative activity. Additionally, the authors claim that fermentation with all strains together gave better antioxidant results than each strain separately, and that the antioxidative activity of soy milk increases with the time of fermentation. Finally, although the antioxidative activity of fermented soya milk was reduced, it was higher than that of unfermented soya milk.

The most popular strain used in the fermentation of soybean-based foods is Bacillus subtilis. Han et al. [38] suggest that B. subtilis-fermented sword beans are potential sources of antioxidants and anti-inflammatory agents. The researchers observed stronger DPPH radical scavenging activity and ferric-reducing antioxidant power in the case of fermented sword beans than in non-fermented beans. In a similar study, $B$. subtilis strain BCRC 14714 exhibited strong antioxidative activity with a DPPH scavenging effect, strong reducing power and ferrous ion chelating effect [39] (Table I).

\section{Animal experiments}

Recent years have seen growing popularity of probiotic products, not only for human use. Some studies have suggested that probiotics may offer potential benefits for domestic animals, such as pigs or chickens. Lactobacillus fermentum has a beneficial influence on antioxidant activity, thereby also on pig health: it has been reported to increase SOD and glutathione peroxidase (GPx) activity, and contribute to a decrease in MDA level in pig serum [40], and hepatic CAT acidity was elevated after probiotic administration. It was also found that $L$. plantarum administration contributes to an increase in the activity of antioxidant enzymes in broiler chicken liver (GPX and CAT) and serum (GPX) and a decrease in MDA level in the serum [41].

Dahi is a traditional yoghurt prepared from buffalo milk. A study co-cultured the milk with selected strains of Bifidobacterium bifidum and Lactobacillus acidophilus and then evaluated its anti-oxidative effects [42]. The control group included standard Dahi without probiotic enrichment and another with buffalo milk. Rats were fed the yoghurt for 110 days. Each month the authors performed an analysis of CAT and SOD activity in red blood cells (RBC).

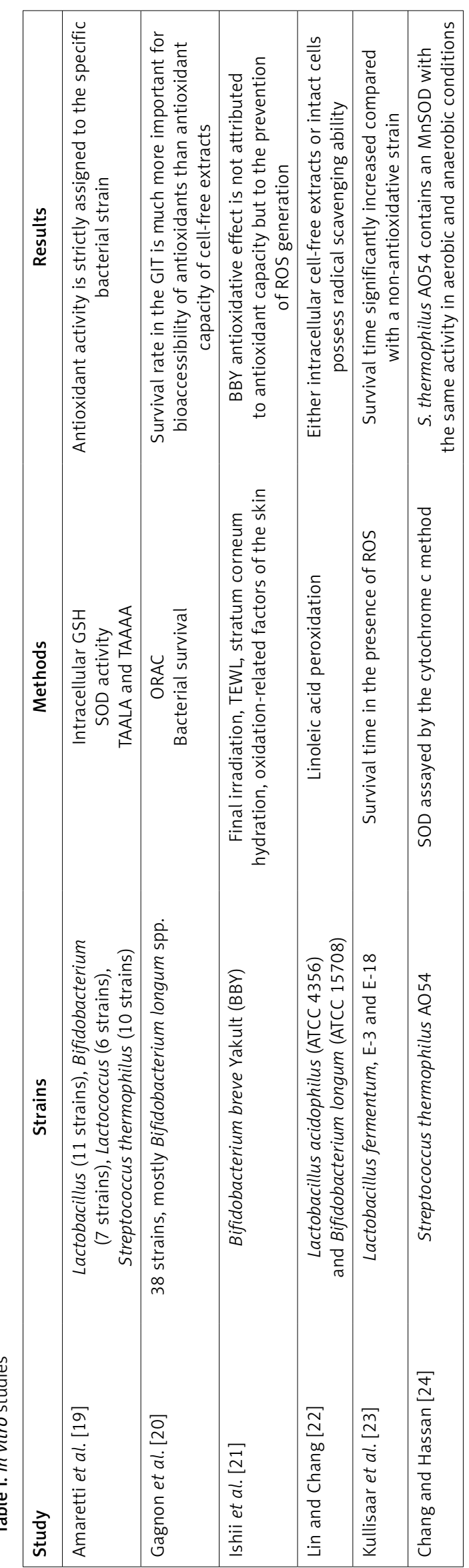




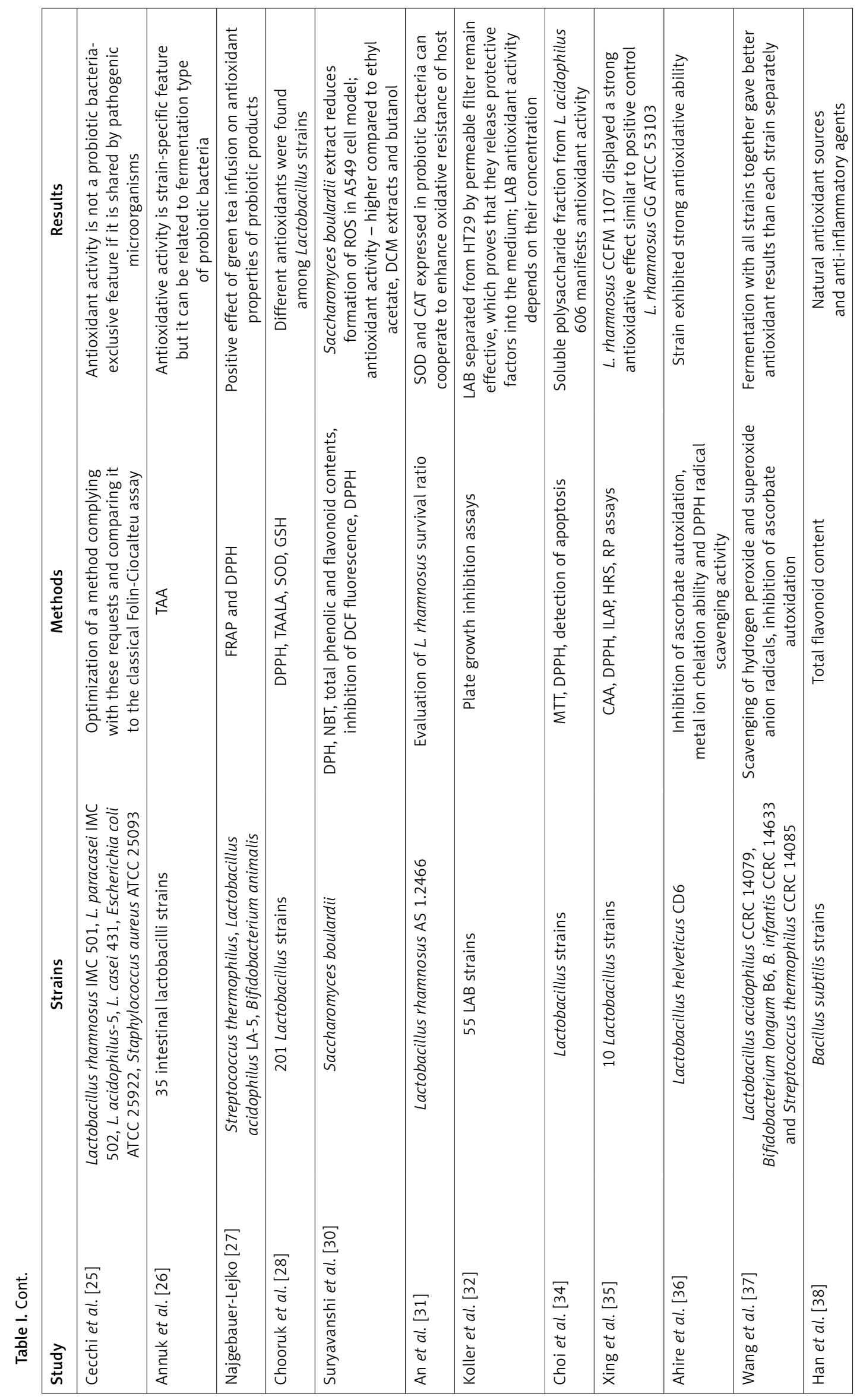


Additionally, at the end of the study an analysis of enzyme activity was performed in colorectal and liver tissue. Superoxide dismutase activity in RBC increased exclusively after probiotic Dahi administration, whereas RBC catalase activity increased more rapidly in the probiotic group. Similarly, SOD and CAT activity was enhanced by the presence of the probiotic in liver (exclusively) and colorectal tissue (as well as standard Dahi). It was concluded that probiotic Dahi efficiently improves antioxidant status in rats.

Another study, conducted on BALB/cJ mice, confirmed that bilberry alone suppresses oxidative stress to a similar degree as a combination of bilberry with Lactobacillus plantarum HEAL19 [43]. Additionally, probiotic administration efficiently reduced damage to the pancreatic tissues of diabetic rats and suppressed streptozotocin-induced oxidative stress [44]. During the study, Dahi supplemented by L. casei NCDC19 and L. acidophilus NCDC14 inhibited lipid peroxidation and maintained the activity of GPx, SOD and CAT. Similarly L. plantarum AS1 demonstrates antioxidant properties, which are additionally involved in the process of $\mathrm{DMH}$ induced carcinogenesis of the rat colon [45].

The administration of selected probiotic strains was found to counteract DOXO-induced oxidative stress and increase the total antioxidant activity of rat plasma [19]. Furthermore, the concentration of GSH in plasma was connected with the dose of administered probiotics. Probiotic administration did not modify oxidative stress indicators or plasma antioxidant activity in unstressed rats. Another study [46] found that probiotic L. casei and $L$. reuteri counteract the hazardous effects of aflatoxin-induced oxidative stress and increase the total antioxidant capacity (TAC) of rat plasma.

Preliminary tests with intracellular cell-free extract showed $72 \%$ inhibition of linoleic acid peroxidation, implying that $L$ casei spp. have possible antioxidant properties [47]. The findings revealed significantly increased activity of CAT, SOD and GPX in $\mathrm{RBC}$ in rats receiving probiotic supplementation. Similarly, significantly higher CAT activity and a slight increase in SOD activity were observed in liver tissue after 90 days of $L$. casei spp. supplementation than in untreated controls. In addition, the probiotic group demonstrated significantly lower levels of lipid peroxidation in rat liver cells and RBC.

Lactobacillus rhamnosus GG (ATCC 53103) (LGG) is one of the most widely used and tested probiotic strains. It was identified as a potential probiotic strain because of its resistance to acid and bile, good growth characteristics and capacity for adhesion to the intestinal epithelial layer. It has various well-documented health effects, including prevention and treatment of gastro-intestinal infections, diarrhea, and stimulation of immune re- sponses. Sun et al. [48] investigated the inhibition of Fe-induced colon oxidative stress in a study on a mouse model. LGG was characterized by longer survival time in the presence of $\mathrm{H}_{2} \mathrm{O}_{2}$ and hydroxyl radicals compared with the mid- and non-antioxidative strains. In addition, LGG efficiently inhibited ferrous Fe accumulation in Fe-overloaded mice. During a similar rat study, it was demonstrated that LGG could modulate the redox state in the colonic fermentation system and inhibit the growth of Enterococcus and Escherichia coli [49].

Grompone et al. [50] performed a notable study that assessed the antioxidative potential of probiotics, particularly Caenorhabditis elegans. This new method provides researchers with not only a fast and convenient method, but also a predictive tool for the screening of new probiotics. In total, 78 strains of Bifidobacterium and Lactobacillus were examined during the study: particular probiotic strains were administered to Caenorhabditis elegans and their survival rate after exposure to hydrogen peroxide was compared with that of a control Escherichia coli OP50 group. The highest antioxidant capacity was revealed by Lactobacillus rhamnosus CNCM I-3690, which increased the average Caenorhabditis elegans lifespan by $20 \%$.

Some studies also focus on probiotic organisms in nature and genetically modify their antioxidant activity. Probiotics may be a vehicle for antioxidant enzymes. Such genetically engineered Lactobacillus plantarum and Lactococcus lactis strains were analyzed in a TNBS colitis Wistar rat model [51]. The modified bacteria, able to produce and release SOD, provided a significantly better anti-inflammatory effect than an infusion of bovine SOD. Elsewhere, manganese SOD producing Lactobacillus gasseri revealed similar strong anti-inflammatory activity in mice [52]. LAB are mostly catalase-negative, but there are some exceptions. Catalase-producing Lactococcus lactis was used in order to increase catalase activity and reduce $\mathrm{H}_{2} \mathrm{O}_{2}$ level in a DMHinduced colon cancer mice model [53]. Numerous lactobacilli were initially screened in vitro for their antioxidative activity [54]. Lactobacillus casei ssp. casei strains exhibiting the highest antioxidative activity were selected for further in vivo studies. The results of linoleic acid peroxidation and microsome-thiobarbituric acid assay indicated that $L$. casei ssp. casei 19 was characterized by maximum antioxidant capacity from among 12 tested strains. In vivo studies indicate that supplementation with selected probiotic strains reduced TBARS values in the LDL fraction of rat plasma, thereby confirming the antioxidative potential of L. casei ssp. casei (Table II).

\section{Survival and stability of probiotics}

Lactobacillus strains are intrinsically acid resistant to a certain extent. In addition, if the pro- 


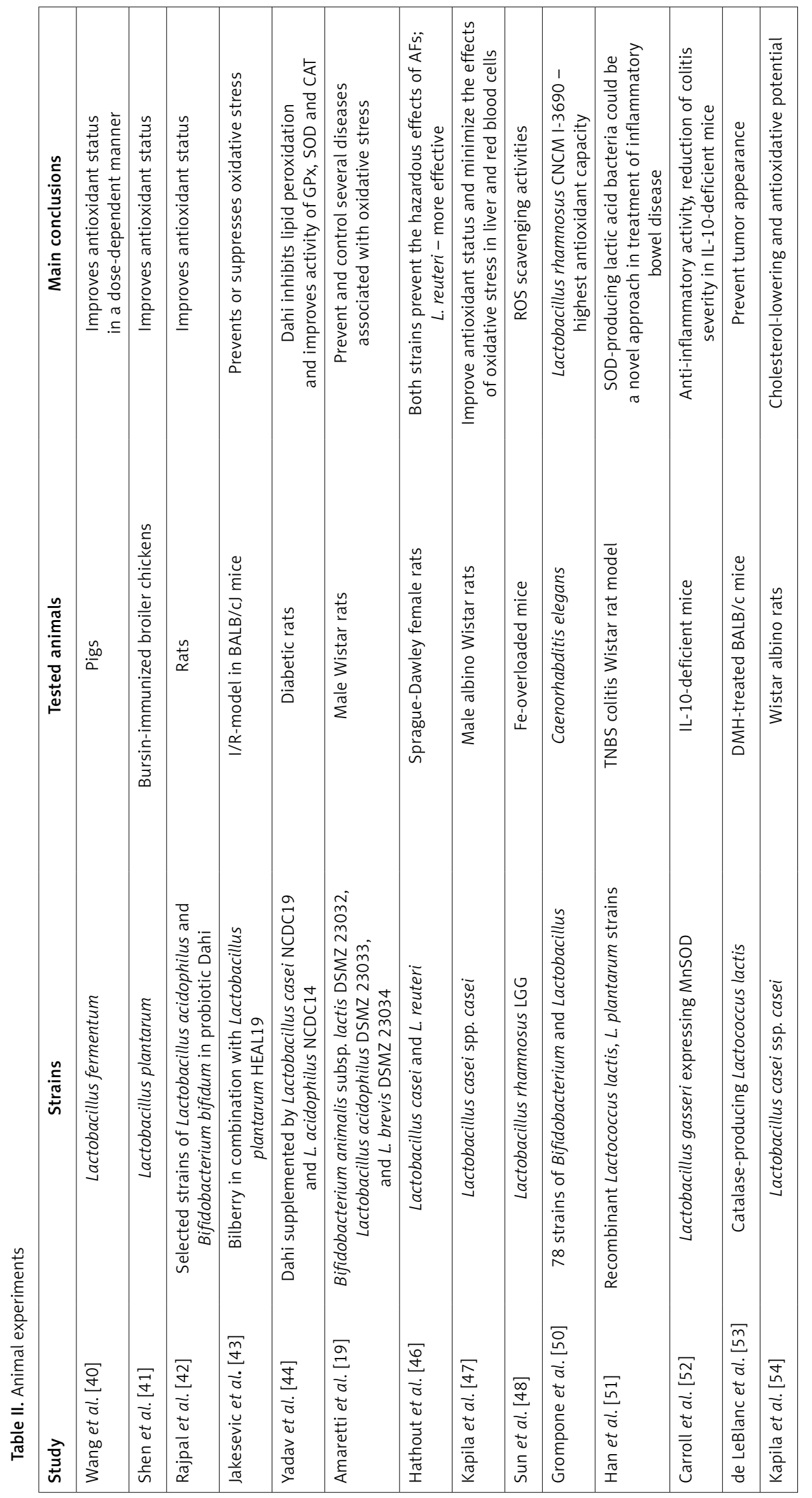


biotics reach the small intestine, they must also demonstrate resistance to bile, which may affect the lipid composition and fatty acid of their cell membranes and decrease the survival of bacteria $[55,56]$.

The most significant variables are concentration and length of exposure to bile salts, stomach acidity and length of exposure and individual properties of the probiotics strains [57]. Some methods are suitable for the simulation of gastro-intestinal conditions [55]. The viability of probiotics at the point of consumption is a factor for the future transit through the adverse conditions of the stomach and/or small intestine [58]. The survival rate of lactic acid bacteria placed in simulated duodenal fluid is correlated with the initial count of bacteria [59]. Recent studies have also confirmed the poor survival of probiotic microorganisms in traditionally fermented dairy products $[60,61]$. Probiotic survival in products may be affected by a broad range of factors, e.g. storage temperature, $\mathrm{H}_{2} \mathrm{O}_{2}$ production, stability in dried or frozen form, $\mathrm{pH}$, post-acidification in fermented products or oxygen toxicity [58, 60-62].

Protective technologies to keep probiotics alive and active during processing and storage are under development. Encapsulation significantly raises probiotic survival. The target of this process is to create a favorable micro-environment in which probiotic bacteria survive processing and will be released in an appropriate place. Studies have demonstrated the benefits of encapsulation regarding protection against adverse conditions [63, 64]. Another study confirmed that Streptococcus thermophilus and Lactobacillus delbrueckii subsp. bulgaricus can be recovered after passage through the gut. Yogurt bacteria evidenced that they can survive transit through the gastrointestinal tract. Nonetheless, permanent selection of improved functional strains and the adoption of new methods to enhance survival are needed to achieve better results in probiotic viability and survival [65].

\section{Human studies}

One study evaluated the effect of Lactobacillus strains on oxidative stress in athletes [66]. In this study, one group consumed a mixture of $L$. paracasei IMC 502 and L. rhamnosus IMC 501 every day for a 4-week period. In the initial part of the study both bacterial strains were examined by the thiobarbituric acid (TBA) method to determine antioxidative activity in vitro and similarly oxidative stress resistance was assessed. As a result, both Lactobacillus strains, in the form of intact cells, similarly inhibit linoleic acid peroxidation, which demonstrated their antioxidative effect, which mostly occurs in intracellular extracts. Additionally, both strains exhibit adequate oxidative stress re- sistance. Subsequently, the biological antioxidant potential of plasma and level of plasma reactive oxygen metabolites were measured in the control and probiotic groups. Participants were required to perform intensive physical activity, which induces intense ROS production and oxidative stress. It was found that two examined strains exerted strong antioxidant activity. Probiotic supplementation contributes to increased plasma antioxidant levels, which leads to ROS neutralization and provides a great opportunity for more extensive use of probiotics. Additionally, feces analysis after probiotic administration showed that the colonization ability of these strains is probably host-specific.

Results obtained by other researchers also confirm the beneficial effects of probiotics [67]. This complex and detailed study investigated the antioxidant efficacy of probiotic capsules and fermented goat milk containing L. fermentum ME-3 among healthy participants. To evaluate human body oxidative status, blood serum from participants was analyzed for total antioxidative status (TAS), total antioxidative activity (TAA) and glutathione redox ratio. Improvement of oxidative stress markers was observed for both formulations: probiotic capsules and fermented goat milk. However, the L. fermentum ME-3 fermented goat milk group demonstrated significantly higher levels of TAA and TAS markers than the capsule group. Additionally, a reduction was observed in the glutathione redox ratio, but only in participants consuming fermented goat milk; this implies the existence of a relationship between the type of formulation and probiotic antioxidant properties inside the host.

However, other studies do not present probiotics in such a positive light regarding oxidative stress. Some species of commensal gut bacteria induced rapid generation of physiological levels of ROS from an unknown source within mammalian epithelial cells that had regulator effects [68-71]. Cellular ROS are often produced via the catalytic action of NADPH oxidases. Moreover, lactobacilli were found to be especially potent inducers of ROS generation in cultured cells and in vivo. According to Neish [72] this effect was demonstrated as an increase in the oxido-reductase reaction of transcriptional factor activations (NF-KB), NrF2 and the antioxidant response element, reflecting a regulated cellular response to increased ROS production.

Another study was conducted on pregnant women in the third trimester. Nine-week consumption of probiotic yogurt enriched with $L$. acidophilus LA5 and Bifidobacterium lactis BB12 did not significantly change erythrocyte GPx, plasma GSH, TAC or serum 8-oxo-G levels in comparison with conventional yogurt [73]. Only erythrocyte 
glutathione reductase (GR) level significantly rose compared to the control group.

A randomized clinical trial conducted by Chamari et al. [74] investigated CAT level in the plasma of healthy women depending on the probiotic supplementation. The probiotic group demonstrated a significant increase in catalase level in comparison with the untreated, i.e. control group. In turn, Lactobacillus casei 01 supplementation did not result in any significant improvement of oxidative status in rheumatoid arthritis (RA) patients compared to placebo [75]. Finally, the beneficial effects of probiotics were also investigated in a group of smokers. Lactobacillus plantarum administration resulted in a significant reduction of plasma $\mathrm{F}_{2}$-isoprostane concentrations (31\%), in comparison with the control group. These biochemical markers are very sensitive and effective in oxidative stress and lipid peroxidation assessment [76] (Table III).

\section{Mechanism of the antioxidant activity of probiotics}

Probiotics can act directly neutralize oxidants by the expression of antioxidant enzymes. One of the best known of these enzymes is SOD. Kullisaar et al. [23] found that L. fermentum E-3 and $\mathrm{E}-18$ were able to express $\mathrm{Mn}$-SOD to resist oxidative stress. Moreover, probiotic bacteria could be very valuable vehicles for many different antioxidant enzymes and allow their local delivery. Recently, it was demonstrated that mice with Crohn's disease receiving engineered, SOD-producing $L$. casei BL23 had faster recovery, increased enzymatic activity in the gut, and a lesser extent of intestinal inflammation than controls [53]. Probiotics are able to produce various metabolites with antioxidant activity, such as butyrate, glu- tathione (GSH) and folate. Clostridium butyricum strain MIYAIRI 588 is a butyrate-producing probiotic which induces antioxidases in rats with nonalcoholic fatty liver disease to suppress hepatic oxidative stress [68]. Probiotics can also inhibit intestinal pathogens and reduce postprandial lipids which are involved in oxidative damage [47, 77]. In the context of its antioxidant activity, the plasma lipid profile is another important factor modulated by probiotic supplementation $[78,79]$.

Many studies have investigated probiotic antioxidant activities, but the mechanism of action still remains unclear. The authors note that exopolysaccharides which are released by probiotic bacteria potentially play a role in the oxidative stress reduction $[80,81]$. The study also compared the antioxidant properties of EPS synthesized by Bacillus coagulans RK-02 with those of vitamins $E$ and C [80]. EPS exhibited significant free radical scavenging and strong antioxidant activities analyzed using various methods. The next experimental work [81] evaluated the effect of EPS producing probiotics on a colitis model in rats. The study confirmed a significantly higher level of MPO in the low-EPS A13 strain group than in the high-EPS B3 group, after induction of oxidative stress. A factor related to the antioxidant properties of probiotics may be their metal chelating abilities; transition metal ions are able to initiate decomposition of hydrogen peroxide into peroxyl and alkoxy radicals or to start lipid peroxidation, thus increasing oxidative stress [82]. Interestingly, some Bifidobacterium spp. cultures may be able to reduce hepatic exposure to intestinal products such as LPS that promote cytokine production and oxidative stress [83]. Lactobacillus spp. may also improve the plasma levels of lipid peroxidation markers [84].

Table III. Human studies

\begin{tabular}{|lccc|}
\hline Study & \multicolumn{1}{c|}{ Strains } & Study groups & Main conclusions \\
\hline Martarelli et al. [66] & $\begin{array}{c}\text { Lactobacillus paracasei IMC 502 } \\
\text { and L. rhamnosus IMC 501 }\end{array}$ & Athletes & $\begin{array}{c}\text { Exert strong antioxidant } \\
\text { activity }\end{array}$ \\
\hline Songisepp et al. [67] & Lactobacillus fermentum ME-3 & $\begin{array}{c}\text { Healthy } \\
\text { volunteer }\end{array}$ & $\begin{array}{c}\text { Increases counts of intestinal } \\
\text { lactobacilli and reduces } \\
\text { oxidative stress }\end{array}$ \\
\hline Asemi et al. [73] & $\begin{array}{c}\text { Lactobacillus acidophilus LA5 } \\
\text { and Bifidobacterium lactis BB12 }\end{array}$ & Pregnant women & $\begin{array}{c}\text { Do not affect oxidative stress } \\
\text { markers, only significantly } \\
\text { increase erythrocyte GR level }\end{array}$ \\
\hline Chamari et al. [74] & $\begin{array}{c}\text { Lactobacillus acidophilus LA5 } \\
\text { and Bifidobacterium lactis BB12 }\end{array}$ & Healthy women & $\begin{array}{c}\text { Consumption of selected } \\
\text { probiotic strain increases } \\
\text { antioxidant enzyme levels and } \\
\text { decreases oxidative stress }\end{array}$ \\
\hline Vaghef-Mehrabany et al. [75] & Lactobacillus casei 01 & $\begin{array}{c}\text { Rheumatoid } \\
\text { arthritis patients }\end{array}$ & $\begin{array}{c}\text { No significant improvement } \\
\text { of oxidative status }\end{array}$ \\
\hline Naruszewicz et al. [76] & Lactobacillus plantarum 299v & Healthy smokers & $\begin{array}{c}\text { Reduction of plasma } \\
\text { F }_{2} \text {-isoprostane concentrations }\end{array}$ \\
\hline
\end{tabular}




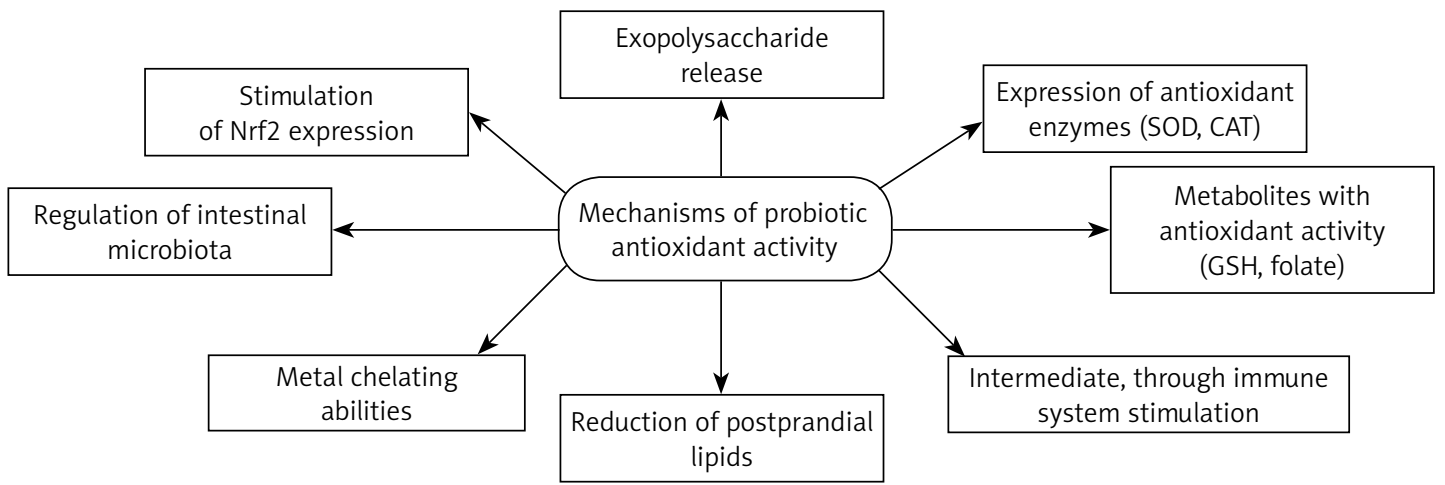

Figure 1. Mechanisms of probiotic antioxidant activity

Total antioxidative ability and resistance to ROS proved to be suitable tools for antioxidative capacity evaluation [85]. The highest antioxidant activity was demonstrated by Lactobacillus casei KCTC 3260, which was assumed to be caused by its very strong chelating activity for ferric ions; the researchers [49] suggest that free radical-scavenging ability is connected with "free" ferrous ion chelating activity and the modulation of redox state in gut chime. Lactobacillus rhamnosus GG (LGG) and L. paracasei Fn032 significantly inhibited the production of $\mathrm{H}_{2} \mathrm{O}_{2}$ induced by ferrous ions. Fn001 successfully inhibited growth of Enterococcus and Escherichia coli related to ferrous ion presence. The peptides released during yoghurt fermentation, and hence their expected antioxidative properties, may play an important role in revealing the probiotic antioxidative mechanism [86]. This mechanisms could even play a major role in many severe diseases. Preclinical studies have documented Lactobacillus rhamnosus GG effects in reducing chronic inflammation associated with cancer development [87]. Nutraceuticals including probiotics are characterized by lipid-lowering properties, important in clinical practice [88]. In vitro tests found that lower molecular weight protein fractions were characterized by stronger antioxidative potential than high molecular weight fractions. It was found that beneficial antioxidant properties are conditioned by the presence of certain free amino acids [89]. In turn, L. plantarum CAI6 and L. plantarum SC4 were investigated in hyperlipidemic mice [90]: the Lactobacillus antioxidative defense mechanism was found to be associated with stimulation of Nrf2 expression in the liver. In another study, probiotic supplementation caused increased levels of mucosal GSH which contributed to attenuated oxidative mucosal damage [91] (Figure 1).

\section{Conclusions}

Careful consideration of the most appropriate species and strains is key to the success of a probiotic antioxidative intervention for a particular pathological condition. However, the European Food Safety Authority (EFSA) has yet not authorized any health claim on probiotics - they can be "potentially" helpful in a number of diseases. Probiotics could be a possible intervention for ischemia-reperfusion injury by reducing ROS generation and lipid peroxidation, as well as increasing SOD activity. Another target for probiotics could be irritable bowel disease. The most commonly used strains are Lactobacillus and Bifidobacterium, which are reported to secrete SOD enzymes and metal-chelating and antioxidant molecules, and could protect the intestine from IBD or even colorectal cancer. Probiotic bacteria capable of local delivery of SOD could open a novel approach to bowel diseases characterized by massive ROS production. Finally, patients experiencing liver disease characterized by strong oxidative stress can benefit from the antioxidant effects of probiotics. To develop novel probiotic products with the potential for preventing oxidative stress, the search for specific probiotic strains which offer the most effective prevention and mitigation of oxidative stress needs to be continued. Other studies are also needed to reveal the complete antioxidative potential of potential probiotics.

\section{Acknowledgments}

This study was supported by grant 503/0-14903/503-01 005 from the Medical University of Lodz.

\section{Conflict of interest}

The authors declare no conflict of interest

\section{References}

1. Ray P, Huang B, Tsuji Y. Reactive oxygen species (ROS) homeostasis and redox regulation in cellular signaling. Cell Signal 2012; 24: 981-90.

2. Song P, Zou MH. Roles of reactive oxygen species in physiology and pathology. In: Atherosclerosis: Risks, Mechanisms, and Therapies. Song P, Zou MH (eds.). John Wiley \& Sons 2015; 379-92. 
3. Mateen S, Moin S, Khan AQ, Zafar A, Fatima N. Increased reactive oxygen species formation and oxidative stress in rheumatoid arthritis. PLoS One 2016; 11: e0152925.

4. Endres L, Begley U, Clark R, et al. Alkbh8 regulates selenocysteine-protein expression to protect against reactive oxygen species damage. PLoS One 2015; 10: e0131335.

5. Ito T, Kimura S, Seto K, et al. Peroxiredoxin I plays a protective role against UVA irradiation through reduction of oxidative stress. J Dermatol Sci 2014; 74: 9-17.

6. Aristatile B, Al-Numair KS, Al-Assaf AH, Veeramani C, Pugalendi KV. Protective effect of carvacrol on oxidative stress and cellular DNA damage induced by UVB irradiation in human peripheral lymphocytes. J Biochem Mol Toxicol 2015; 29: 497-507.

7. Lü JM, Lin P, Yao Q, Chen C. Chemical and molecular mechanisms of antioxidants: experimental approaches and model systems. J Cell Mol Med 2010; 14: 840-60.

8. Schiavone S, Jaquet V, Trabace L, Krause KH. Severe life stress and oxidative stress in the brain: from animal models to human pathology. Antioxid Redox Signal 2013; 18: 1475-90.

9. Burton GJ, Jauniaux E. Oxidative stress. Best Pract Res Clin Obstet Gynaecol 2011; 25: 287-99.

10. Rahal A, Kumar A, Singh V, et al. Oxidative stress, prooxidants, and antioxidants: the interplay. Biomed Res Int 2014; 2014: 761264.

11. Schafer FQ, Buettner GR. Redox environment of the cell as viewed throuhg the redox state of the glutathione disulfide/glutathione couple. Free Radic Biol Med 2001; 30: 1191-212

12. Poljsak B. Strategies for reducing or preventing the generation of oxidative stress. Oxid Med Cell Longev 2011; 2011: 194586

13. Hybertsona BM, Gaoa B, Bosea S, McCorda JM. Oxidative stress in health and disease: the therapeutic potential of Nrf2 activation. Mol Aspects Med 2011; 32: 234-46.

14. Verna EC. Use of probiotics in gastrointestinal disorders: what to recommend? Therap Adv Gastroenterol 2010; 3: 307-19.

15. Callaway TR, Edrington TS, Anderson RC, et al. Probiotics, prebiotics and competitive exclusion for prophylaxis against bacterial disease. Anim Health Res Rev 2008; 9: 217-25.

16. Ashraf R, Shah NP. Immune system stimulation by probiotic microorganisms. Crit Rev Food Sci Nutr 2014; 54 : 938-56.

17. Spyropoulos BG, Misiakos EP, Fotiadis C, Stoidis CN Antioxidant properties of probiotics and their protective effects in the pathogenesis of radiation-induced enteritis and colitis. Dig Dis Sci 2011; 56: 285-94.

18. Kanmani P, Satish Kumar R, Yuvaraj N, Paari KA, Pattukumar V, Arul V. Probiotics and its functionally valuable products - a review. Crit Rev Food Sci Nutr 2013; 53: 641-58.

19. Amaretti A, di Nunzio M, Pompei A, Raimondi S, Rossi M, Bordoni A. Antioxidant properties of potentially probiotic bacteria: in vitro and in vivo activities. Appl Microbiol Biotechnol 2013; 97: 809-17.

20. Gagnon M, Savard P, Riviére A, LaPointe G, Roy D. Bioaccessible antioxidants in milk fermented by Bifidobacterium longum subsp. longum strains. Biomed Res Int 2015; 2015: 169381.

21. Ishii Y, Sugimoto S, Izawa N, Sone T, Chiba K, Miyazaki K. Oral administration of Bifidobacterium breve attenuates UV-induced barrier perturbation and oxidative stress in hairless mice skin. Arch Dermatol Res 2014; 306: 463-73.
22. Lin MY, Chang FJ. Antioxidative effect of intestinal bac teria Bifidobacterium longum ATCC 15708 and Lactobacillus acidophilus ATCC 4356. Dig Dis Sci 2000; 45: 1617-22.

23. Kullisaar T, Zilmer M, Mikelsaar M. Two antioxidative lactobacilli strains as promising probiotics. Int J Food Microbiol 2002; 72: 215-24.

24. Chang SK, Hassan HM. Characterization of superoxide dismutase in Streptococcus thermophilus. Appl Environ Microbiol 1997; 63: 3732-35.

25. Cecchi T, Savini M, Silvi S, Verdenelli MC, Cresci A. Optimisation of the measurement of the antioxidant activity of probiotics and pathogens: a crucial step towards evidence-based assessment of health claims and production of effective functional foods. Food Anal Methods 2015; 8: 312-20.

26. Annuk H, Shchepetova J, Kullisaar T, Songisepp E, Zilmer M, Mikelsaar M. Characterization of intestinal lactobacilli as putative probiotic candidates. J Appl Microbiol 2003; 94: 403-12.

27. Najgebauer-Lejko D. Effect of green tea supplementation on the microbiological, antioxidant, and sensory properties of probiotic milks. Dairy Sci Technol 2014; 94: 327-39.

28. Chooruk A, Piwat S, Teanpaisan R. Antioxidant activity of various oral Lactobacillus strains. J Appl Microbiol 2017; 123: 271-9.

29. Liu CF, Pan TM. In vitro effects of lactic acid bacteria on cancer cell viability and antioxidant activity. J Food Drug Anal 2010; 18: 77-86.

30. Suryavanshi A, Agarwal A, Kaler A, et al. Comparative studies on the antioxidant potential of vanillin-producing Saccharomyces boulardii extracts. Oxid Antioxid Med Sci 2013; 2: 201-9.

31. An H, Zhai Z, Yin S, Luo Y, Han B, Hao Y. Coexpression of the superoxide dismutase and the catalase provides remarkable oxidative stress resistance in Lactobacillus rhamnosus. J Agric Food Chem 2011; 59: 3851-56.

32. Koller VJ, Marian B, Stidl R, et al. Impact of lactic acid bacteria on oxidative DNA damage in human derived colon cells. Food Chem Toxicol 2008; 46: 1221-9.

33. Ljungh A, Wadström T. Lactic acid bacteria as probiotics. Curr Issues Intest Microbiol 2006; 7: 73-89.

34. Choi SS, Kim Y, Han KS, You S, Oh S, Kim SH. Effects of Lactobacillus strains on cancer cell proliferation and oxidative stress in vitro. Lett Appl Microbiol 2006; 42: 452-8.

35. Xing J, Wang G, Zhang Q, et al. Determining antioxidant activities of lactobacilli cell-free supernatants by cellular antioxidant assay: a comparison with traditional methods. PLoS One 2015; 10: e0119058.

36. Ahire JJ, Mokashe NU, Patil HJ, Chaudhari BL. Antioxida tive potential of folate producing probiotic Lactobacillus helveticus CD6. J Food Sci Technol 2013; 50: 26-34.

37. Wang YC, Yu RC, Chou CC. Antioxidative activities of soymilk fermented with lactic acid bacteria and bifidobacteria. Food Microbiol 2006; 23: 128-35.

38. Han SS, Hur SJ, Lee SK. A comparison of antioxidative and anti-inflammatory activities of sword beans and soybeans fermented with Bacillus subtilis. Food Funct 2015; 6: 2736-48.

39. Lin CC, Wu PS, Liang DW, Kwan CC, Chen YS. Quality, antioxidative ability, and cell proliferation-enhancing activity of fermented black soybean broths with various supplemental culture medium. J Food Sci 2012; 77: C95-101.

40. Wang AN, Yi XW, Yu HF, Dong B, Qiao SY. Free radical scavenging activity of Lactobacillus fermentumin vitro 
and its antioxidative effect on growing-finishing pigs. J Appl Microbiol 2009; 107: 1140-8.

41. Shen X, Yi D, Ni X, et al. Effects of Lactobacillus plantarum on production performance, immune characteristics, antioxidant status and intestinal microflora of bursinimmunized broilers. Can J Microbiol 2014; 60: 193-202.

42. Rajpal S, Kansal VK. Probiotic Dahi containing Lactobacillus acidophilus and Bifidobacterium bifidum stimulates antioxidant enzyme pathways in rats. Milchwissenschaft 2009; 64: 287-90.

43. Jakesevic M, Aaby K, Borge GI, Jeppsson B, Ahrné S, Molin G. Antioxidative protection of dietary bilberry, chokeberry and Lactobacillus plantarum HEAL19 in mice subjected to intestinal oxidative stress by ischemia-reperfusion. BMC Complement Altern Med 2011; 8: $1472-82$

44. Yadav H, Jain S, Sinha PR. Oral administration of dahi containing probiotic Lactobacillus acidophilus and Lactobacillus casei delayed the progression of streptozotocininduced diabetes in rats. J Dairy Res 2008; 75: 189-95.

45. Kumar RS, Kanmani P, Yuvaraj N, et al. Lactobacillus plantarum AS1 isolated from south Indian fermented food Kallappam suppress 1,2-dimethyl hydrazine (DMH)induced colorectal cancer in male Wistar rats. Appl Biochem Biotechnol 2012; 166: 620-31.

46. Hathout AS, Mohamed S, El-Nekeety AA, Hassan N, Aly SE, Abdel-Wahhab M. Ability of Lactobacillus casei and Lactobacillus reuteri to protect against oxidative stress in rats fed aflatoxins-contaminated diet. Toxicon 2011; 58 179-86.

47. Kapila S, Kapila R, Reddi S, Sinha PR. Oral administration of probiotic Lactobacillus casei spp. casei ameliorates oxidative stress in rats. Int J Curr Microbiol App Sci 2014; 3: 670-84.

48. Sun J, Hu XL, Le GW, Shi YH. Inhibition of Fe-induced coIon oxidative stress by lactobacilli in mice. World J Microbiol Biotechnol 2013; 29: 209-16.

49. Sun J, Hu XL, Le GW, Shi YH. Lactobacilli prevent hydroxy radical production and inhibit Escherichia coli and Enterococcus growth in system mimicking colon fermentation. Lett Appl Microbiol 2010; 50: 264-9.

50. Grompone G, Martorell P, Llopis S, et al. Anti-inflammatory Lactobacillus rhamnosus CNCM I-3690 strain protects against oxidative stress and increases lifespan in Caenorhabditis elegans. PLoS One 2012; 7: 52493.

51. Han W, Mercenier A, Ait-Belgnaoui A. Improvement of an experimental colitis in rats by lactic acid bacteria producing superoxide dismutase. Inflamm Bowel Dis 2006; 12: 1044-52.

52. Carroll IM, Andrus JM, Bruno-Bárcena JM, Klaenhammer TR, Hassan HM, Threadgill DS. Anti-inflammatory properties of Lactobacillus gasseri expressing manganese superoxide dismutase using the interleukin 10-deficient mouse model of colitis. Am J Physiol Gastrointest Liver Physiol 2007; 293: G729-38.

53. de Moreno de LeBlanc A, LeBlanc JG, Perdigón G, et al. Oral administration of a catalase-producing Lactococcus lactis can prevent a chemically induced colon cancer in mice. J Med Microbiol 2008; 57: 100-5.

54. Kapila S, Vibha, Sinha PR. Antioxidative and hypocholesterolemic effect of Lactobacillus casei ssp casei (biodefensive properties of lactobacilli). Indian J Med Sci 2006; 60: 361-70.

55. Botes M. Survival of probiotic lactic acid bacteria in the intestinal tract, their adhesion to epithelial cells and their ability to compete with pathogenic microorganisms. Dissertation, University of Stellenbosch 2008.
56. Corcoran BM, Stanton C, Fitzgerald GF, Ross RP. Survival of probiotic Lactobacilli in acidic environments is enhanced in the presence of metabolizable sugars. Appl Environ Microbiol 2005; 71: 3060-7.

57. Bezkorovainy A. Probiotics: determinants of survival and growth in the gut. Am J Clin Nutr 2001; 73: 399-405.

58. Kailasapathy K. Microencapsulation of probiotic bacteria: technology and potential applications. Curr Issues Intest Microbiol 2002; 3: 39-48.

59. Ziarno M. Survival of lactic acid bacteria in simulated duodenal fluid depending on cholesterol presence. Pol J Food Nutr Sci 2007; 57: 625-31.

60. Shah NP. Probiotic bacteria: selective enumeration and survival in dairy foods. J Dairy Sci 2000; 83: 894-907.

61. Lourens-Hattingh A, Viljoen BC. Review: yoghurt as probiotic carrier in food. Int Dairy J 2001; 11: 1-17.

62. Kailasapathy K, Chin J. Survival and therapeutic potential of probiotic organisms with reference to Lactobacillus acidophilus and Bifidobacterium spp. Immunol Cell Biol 2000; 78: 80-8.

63. Kanmani P, Kumar RS, Yuvaraj N, Paari KA, Pattukumar V, Aru V. Cryopreservation and microencapsulation of a probiotic in alginate-chitosan capsules improves survival in simulated gastrointestinal conditions. Biotechnology and Bioprocess Engineering 2011; 16: 1106-14.

64. D’Orazio G, Di Gennaro P, Boccarusso M, et al. Microencapsulation of new probiotic formulations for gastrointestinal delivery: in vitro study to assess viability and biological properties. Appl Microbiol Biotechnol 2015; 99: 9779-89.

65. Elli M, Callegari ML, Ferrari S, Bessi E. Survival of yogurt bacteria in the human gut. Appl Environ Microbiol 2006; 72: 5113-7.

66. Martarelli D, Verdenelli MC, Scuri S, et al. Effect of a probiotic intake on oxidant and antioxidant parameters in plasma of athletes during intense exercise training. Curr Microbiol 2011; 62: 1689-96.

67. Songisepp E, Kals J, Kullisaar T, et al. Evaluation of the functional efficacy of an antioxidative probiotic in healthy volunteers. Nutr J 2005; 4: 22.

68. Kumar A, Wu H, Collier-Hyams LS, et al. Commensal bacteria modulate cullin-dependent signaling via generation of reactive oxygen species. EMBO J 2007; 26: 4457-66.

69. Kumar A, Wu H, Collier-Hyams LS, Kwon YM, Hanson JM, Neish AS. The bacterial fermentation product butyrate influences epithelial signaling via reactive oxygen species-mediated changes in cullin-1 neddylation. J Immunol 2009; 182: 538-46.

70. Wentworth CC, Alam A, Jones RM, Nusrat A, Neish AS. Enteric commensal bacteria induce ERK pathway signaling via formyl peptide receptor (FPR)-dependent redox modulation of dual specific phosphatase 3 (DUSP3). J Biol Chem 2011; 286: 38448-55.

71. Swanson PA $2^{\text {nd }}$, Kumar A, Samarin S, et al. Enteric commensal bacteria potentiate epithelial restitution via reactive oxygen species-mediated inactivation of focal adhesion kinase phosphatases. Proc Natl Acad Sci U S A 2011; 108: 8803-8.

72. Neish AS. Redox signaling mediated by the gut microbiota. Free Radic Res 2013; 47: 950-7.

73. Asemi Z, Jazayeri S, Najafi M, et al. Effect of daily consumption of probiotic yogurt on oxidative stress in pregnant women: a randomized controlled clinical trial. Ann Nutr Metab 2012; 60: 62-8.

74. Chamari M, Djazayery A, Jalali M. The effect of daily consumption of probiotic and conventional yogurt on some 
oxidative stress factors in plasma of young healthy women. ARYA Atheroscler J 2008; 4: 175-9.

75. Vaghef-Mehrabany E, Alipour B, Homayouni-Rad A, Sharif SK, Asghari-Jafarabadi M, Zavvari S. Probiotic supplementation improves inflammatory status in patients with rheumatoid arthritis. Nutrition 2014; 30: 430-5.

76. Naruszewicz M, Johansson ML, Zapolska-Downar D, Bukowska H. Effect of Lactobacillus plantarum 299v on cardiovascular disease risk factors in smokers. Am J Clin Nutr 2002; 76: 1249-55.

77. Mikelsaar M, Zilmer M. Lactobacillus fermentum ME-3 an antimicrobial and antioxidative probiotic. Microb Ecol Health Dis 2009; 21: 1-27.

78. Banach M, Jankowski P, Jóźwiak J, et al. Guidelines for the management of dyslipidaemias for family physicians 2016. Arch Med Sci 2017; 13: 1-45.

79. Ursoniu S, Sahebkar A, Serban MC, Banach M. Lipid profile and glucose changes after supplementation with astaxanthin: a systematic review and meta-analysis of randomized controlled trials. Arch Med Sci 2015; 11: 253-66.

80. Kodali VP, Sen R. Antioxidant and free radical scavenging activities of an exopolysaccharide from a probiotic bacterium. Biotechnol J 2008; 3: 245-51.

81. Sengul N, Aslým B, Ucar G. Effects of exopolysaccharide producing probiotic strains on experimental colitis in rats. Dis Colon Rectum 2006; 49: 250-8.

82. Spyropoulos BG, Misiakos EP, Fotiadis C, Stoidis CN. Antioxidant properties of probiotics and their protective effects in the pathogenesis of radiation-induced enteritis and colitis. Dig Dis Sci 2011; 56: 285-94.

83. Nobili V, Putignani L, Mosca A, et al. Bifidobacteria and lactobacilli in the gut microbiome of children with non-alcoholic fatty liver disease: which strains act as health players. Arch Med Sci 2018; 14: 81-7.

84. Vespasiani-Gentilucci U, Gallo P, Picardi A. The role of intestinal microbiota in the pathogenesis of NAFLD: starting points for intervention. Arch Med Sci 2018; 14: 701-6.

85. Lee J, Hwang KT, Chung MY, Cho DH, Park CS. Resistance of Lactobacillus casei KCTC 3260 to reactive oxygen species (ROS): role for a metal ion chelating effect. J Food Sci 2005; 70: 388-91.

86. Farvin KHS, Baron CP, Nielsen NS, Jacobsen C. Antioxidant activity of yoghurt peptides: part 1 - in vitro assays and evaluation in $\mathrm{u}-3$ enriched milk. Food Chem 2010; 123: 1081-9.

87. Banna GL, Torino F, Marletta F, et al. Lactobacillus rhamnosus GG: an overview to explore the rationale of its use in cancer. Front Pharmacol 2017; 8: 603.

88. Cicero AFG, Colletti A, Bajraktari G, et al. Lipid lowering nutraceuticals in clinical practice: position paper from an International Lipid Expert Panel. Arch Med Sci 2017; 13: 965-1005

89. Farvin KHS, Baron CP, Nielsen NS, Otte J, Jacobsen C. Antioxidant activity of yoghurt peptides: part 2 - characterisation of peptide fractions. Food Chem 2010; 123: 1090-7.

90. Wang LX, Liu K, Gao DW, Hao JK. Protective effects of two Lactobacillus plantarum strains in hyperlipidemic mice. World J Gastroenterol 2013; 19: 3150-6.

91. Lutgendorff F, Nijmeijer RM, Sandstrom PA, Trulsson LM, Magnusson KE, Timmerman HM. Probiotics prevent intestinal barrier dysfunction in acute pancreatitis in rats via induction of ileal mucosal glutathione biosynthesis. PLoS One 2009; 4: e4512. 